Josep Maria Esquirol

\title{
Network and Everyday Life: Beyond “Local Space”?
}

\section{Abstract:}

After describing what it is known as quotidianity - or everyday life-, the text focuses on the way it is influenced by the Network, paying special attention to the space-time experience. How does the Network flow determine a new temporality? How does Cyberspace interact with the place? To finish with, we comment on the opinion according to which Cyberspace goes beyond the boundaries of what is local.

\section{Agenda}

Everyday life

"Global Speed"

Connections and flows in global society

Too full

Cyberspace and "exceeding" of the place

\section{Author:}

Josep Maria Esquirol:

- Universitat de Barcelona, Baldiri i Reixac, 08028 Barcelona (Spain)

- $\square$ imesquirol@ub.edu, 邑 www.fundacion-epson.es

- Relevant publications:

- Tres ensayos de filosofía política, EUB, Barcelona, 1996

- La frivolidad política del final de la historia, Caparrós, Madrid, 1998

- "Ortega y Gasset: la dimension anthropologique de la technique et le diagnostic de l'«homme de masse»" in Hottois, G., Les Philosophes et la Technique, Vrin, Paris, 2003. 


\section{Everyday life}

The purpose of these pages is not to carry out an exhaustive and systematic analysis of social or economic change taking place nowadays in Catalan society. Their purpose is less ambitious. I could perhaps call it, were it not for the vagueness of this expression, a reflection on everyday life, and on the background changes this is undergoing as a consequence of network-society, or global society.

Let us start by a succinct characterization of quotidianity. As indicated by the very expression, quotidian life is that life people may live most of the days; Therefore, the feature of quotidianity is repetition or routine; sometimes, in our lifetime, "extraordinary", surprising or very special things happen. Extraordinary things can be "normal" (I know this is apparently a contradiction), but they are extraordinary to whom is living them precisely because of their singularity and because they are not a part of any routine. Thus, for instance, it is quite normal for people to have children but it is not normal for people to have children every day. This is why the experience of the birth of a child does not fit any pattern or routine; it is quite normal that people fall in love but it is not so normal that a person falls in love every day, therefore falling in love does not fit any pattern either.

Quotidian life is the framework for satisfaction of needs such as feeding or sleeping, and also, in part, the satisfaction of wishes; quotidianity is the place for human relations -with work companions, with other members of the family, with friends entailing pleasures, reconnaissance and conflicts derived from them. Quotidianity is also the place for language - it is filled with gestures and words.

Why is it sometimes difficult to continue enduring quotidianity? Simply because no big projects or dreams are completed in it. This is why we cannot quit dreaming- because it is one of the ways to exit the Empire of quotidianity. And we say "exit" because, indeed, quotidianity becomes a sort of "whole", of world, and it is not quotidianity itself what weights on us but its hegemony. This partially explains the necessity to escape and to have provisional breaks: week-end trips (it will not take us long to integrate them into the same quotidianity) travels, holidays... and other typologies of evasion, such as those achieved by means of drugs, music or reading (obviously resulting into different consequences).
Technique has a significant role in the definition of quotidianity. Do we realize how much did quotidian life change by introducing running water and drains? And electric current? And all the generation of domestic goods, namely washing machine, fridge, dishwasher, iron...Technique delimits and determines an actuation field, a typology of behavior, some rhythms, and some experiences. And also a space-time experience. It is in this one that I want to insist.

\section{"Global Speed"}

We are not wondering, for instance, whether nowadays we work more or less than we used to do before; it is something quite different. We mean that work itself is structured by a "fast timing". We will explain this with by proposing a contrast. Do you know which was the timetable in a Medieval Benedictine community? The timetable was the framework to all community activities and what ruled the monks' life. This schedule varied according to the course of the Sun and the seasons; however, avoiding now such variations, this was approximately the schedule: Monks woke up around 2:00 a.m; they attended the Vigils or Night Office (matins). This office was said to last for about one hour and a half, and was followed by an interval of about one hour devoted by the community to study the Psalms and Lessons, or to pray. Thus they reached the Morning Office (Lauds). This way, the first hours of the day were devoted to God's praise; the rest of the day was devoted to handicrafts and to lectio divina, occupations that were interrupted four times by the four minor hours of canonical office: Prime, Terce, Sext and None, that were not long. The only daily meal took place, in winter, at 2:30 p.m. In summer, there were lunch (about 12 a.m) and supper (at about 6:00 p.m); after lunch, monks enjoyed a midday sleep (lasting about two hours). In the afternoon they gathered to listen to some readings, sang the Complines and retired to their bedrooms. All in all, Monks devoted four hours and a half to the Divine Office, one hour to Meditatio, three and a half to read, six to work, one to eat and eight to sleep. Let us ask again: what did schedule their time? Basically, day and night, the Sun's movement. And how fast is the Sun? We already know that, half a day mean half a turn in the Sky. It never stops but it runs at a reasonable speed (at least, from what we can perceive). Timing, therefore, from the course of the Sun and the hours. On the other hand, we need to consider that the above explained schedule was that of a Monk and therefore very much structured by the 
offices. Naturally, the schedule of a peasant was much more fluent and fitted even more perfectly the Sun's movement. In agricultural work, exact timing was not very important and expressions as this to follow were most likely: "it's about two". It is obvious that from then on many things have happened, also in time paradigms, but let us jump to nowadays: What do we have now that becomes the reference (like day and hours used to be in old times)? I should say the answer has to go in this direction: the course of the Sun has been replaced by the speed of information, and the "about..." of the hours has been replaced by the minutes and the seconds. Our life, curiously, is now more marked by time. One could say, using an assessing tone (worthy to pay attention to though), that there is too much time, too much mastery of time. Sun never sets in the Internet; there is no day or night, only minutes and seconds. This is why the old references to parts of the day are becoming progressively eroded: morning, afternoon, evening, night. A homogeneous time totally disintegrated into these small units. Mainly, people's everyday life is and will be more determined by such time parameters. And, above all, one experiences speed not because we do not devote certain hours to meals, certain to work and certain to sleep, but because the leading movement is not anymore that of the Sun, but that of information. It is this information that moves quickly from one place to another, and makes people perceive such speed in the environment and in the own quotidianity.

In everyday language, it is frequent to find these expressions: "two seconds!", "in ten minutes"...

In Catalonia, the rural world, still preserving vestiges of traditional time parameters, is quickly lining up with this global time, and I think the change to be quite deep and effective.

\section{Connections and flows in global society}

Linked to this, I should add another feature that, coming from technology, noticeably designs quotidian life. Internet is the global connection, the paradigm of connection. However, this does not only affect Internet. In general, in our world, communication Networks of many types have been built up partly matching up with the phenomenon of globalisation. We can therefore say that "everything is connected". Well, also life is connected. Our everyday life is becoming increasingly conditioned by this technological connectivity. The development of telephony (and now especially, mobile telephony), electronic mail, Internet, surveillance systems (at work, motorways and public spaces...) has led us to this situation. Thanks to the development of telephony, we already talk over the phone everywhere: in a car, in the office, at home.... even watching our interlocutors meanwhile. I guess it will not take long till videoconferences become as present in everyday life as mobile phones already are. In fact, new generations of mobile telephony already incorporate electronic mail and videoconference. Electronic connectivity is so flexible that it keeps us company everywhere we go.

Obviously, a multiplication of passwords comes up linked to this connectivity. Systems and networks demand passwords to gain access to "personal" areas. Thus, we have passwords to enter Internet, our e-mail, our credit card, bank accounts, mobile phones... To the traditional ID number many other numbers and keywords are being added, perhaps they will unify in the future. In any case, their presence in everyday life is nowadays outstanding.

Connected life is technological design. Connection gadgets and tools will soon be so glued to us that we will not separate from them anymore. I do not know to which extend do we realise it, but this change is really spectacular. Some fiction creations (cinema, literature) have already set sight on this and although this is not relevant to the purpose of this paper, the truth is that connectivity and connection are a reality increasingly affecting and defining people's life.

However, one thing is connection and a different one is what runs through these connections. What does it go through them? Flows, information packages that run, as we mentioned before, at a high speed. What I would like to stress now is not as much the speed as the idea of flow. Let us realise that images and metaphors regarding this reality are increasingly usual: flows of people, of money, information. The fact that new info technologies can be best represented by the image of flow helps to define people's life also from this image. In a sense, this is a very old image. The reference of wise Heraclitus to the river flow in order to manifest that everything is change is framed within this direction. Nonetheless, today this image becomes most effective: many domains of life perfectly fit the scheme of flow. In our days, the struggle is not between permanence and erosion but between permanence (or identity) and flow. One thing is the destructor time, the ageing time, the eroding time, and a different one is the dissolution into the flow, 
the river, the stream... Hence we decreasingly perceive life as a certain resistance to change, and increasingly as an expression of the flow. Us as information transmitters, as function transmitters...transmitters and transmitted. The flow, like the river, always changes, therefore everything becomes extraordinarily evanescent, everything expires quickly, headlines from yesterday are prehistory today, are nothing; flow is substituted by more flow. Information is substituted by new information, without traumas, "naturally", fluently. Some people are substituted by other people. We do not perceive ourselves as much under Darwinian images of struggle and conflict as under those images of functions and flow transmission, painful individually but ordinary and without problems as a whole.

The parameter of flow, quite present in big cities (like Barcelona), is also spreading to rural world, also contributing to erase boundaries between urban and rural experience.

\section{Too full}

Urban life (emblematic demonstration of technification) engages the majority of people into a very busy life. I would not call it a specially hard life, but better a very full life... It is anguishing, for instance, to realise how busy "children agendas" are: after eight hours of school, out-of-school activities on working days, also during the week-end - language courses, sports, music...Do they have time to rest, play, do nothing, get bored? In other words: do they have time at all? Obviously, this is all a paradoxical effect resulting from children's imitation of adult life, of whom most of us complain.

Indeed, the majority of us are snowed under with too much activity and do not stop repeating that we have no time. Family (children, parents, partner), friends, work -increasingly demanding-, training, cultural life, necessary distraction, sport... The day is 24 hours long, the week is 7 days long. We tell ourselves this is a matter of priorities and it is partially true but, above all, it is a problem of time. There is no time for everything, we can neither do nor achieve everything... but the technological context (connectivity, speed, information...) wraps us up into this trend. There are hundreds of proposals likely to fill in the gaps in our lives. A good percentage of advertising is nothing but the struggle between all these alternative proposals (or identical proposals with different trademarks).
To this it has to be added the paperwork issue; bureaucracy and procedures: papers, forms, applications, receipts, summaries, notifications, lawsuits, reports...Why most of the times does automatism complicate things instead of simplify them?

The word that has overcrowded psychologist offices and spa centres is stress. Within the world of Information and Communication technologies, everyday life tends to be a stressed life. Therefore the success of antistress remedies: pills, yoga, relaxation, massages, herbs, sport, trips to the countryside... Sometimes, remedies work out, partially at least, but hidden beneath there is the real problem: our lifestyle. We have a stressing lifestyle and the only radical solution is to switch into a different one. Therefore, North-American society (and the like) have spawned movements for "simple life": work less, spend less, consume less... live differently. Nonetheless, these alternative movements do nothing but confirm the diagnose: predominant lifestyle is that of (over)activity and excess.

I do not mean that there is an essential and necessary relationship between network society and (hyper) activity, but there is a concomitance and, certainly, within a technological context like the one we know, it is easier to imagine - because we have it in front of us- a very busy everyday life than a "simpler and less accelerated life".

\section{Cyberspace and "exceeding" of the place}

Space is a major philosophical issue, this does not need further comments (from Plato's chora to Heidegger's Dasein spatiality, two millennium and a half of uninterrupted reflection). However, it may seem rather eccentric to translate this philosophical question to the subject of what has been called "cyberspace".

Even if there exists a certain linguistic anarchy regarding the world increasingly opened by information and communication technologies, some words start to be used with very delimited meanings. For instance, "cyberspace", which is not precisely a simple word, has basically two meanings. On the one hand, it is used to designate that space of data people can "navigate", as Internet users do through the World Wide Web. And, on the other, it is also used to designate virtual reality: that world of threedimensional images, created by digital technology, we 
can plunge into thanks to the person-computer interface. These virtual environments, ranging from more or less perfected games, to simulations in domains of professional learning (surgery, aviation, astronautics, military strategy...) are, besides, interactive environments, that is to say, not only do we find ourselves into these enveloping worlds, these virtual contexts, but we can also modify them, act on them. By "cyberspace", then, we mean both the network of data and the virtual reality or environment. While this second "world" is presented to us as such (phenomenologically, it is given to us as something perfectly explicit), the network is something we must imagine because, in fact, we cannot see it; within the $W W W$, one can move all over and can imagine the network as the "space" one is moving around. However, with technological breakthrough, this elementary navigation in the network is most likely to become a navigation-actuation within an explicit virtual environment. Therefore, by "cyberspace" we would mean one sole thing.

It is important to bear in mind that our space-time experience is in the basement of all our further experiences (which we can acknowledge although we do not accept Kant's thesis on space and time being $a$ priori forms of our sensitivity). Therefore, the influence of cyberspace on our space-time experience will be really significant.

I believe it is possible to portray cyberspace as an "evolution" of the urban or as a hyper city; telepolis as a radicalisation and evolution of metropolis. If, compared to rural world, the city entails a loss of space and orientation, in its turn, compared to the city, cyberspace entails the disallowance of space ("rich" space) and a higher degree of disorientation.

There is no need to set off from romantic premises in order to recognise the specific orientation of rural world. However little one may have experienced and lived this reality (of whom, nowadays few expressions remain in developed countries), it is well known that rural world is much more oriented than urban world. A small nucleus of houses surrounded by fields, forests and mountains, with isolated farms spread around within a territory; the belfry, up above the roofs is the first thing one can see from afar. It constitutes one of the reference points, not only regarding space, because also the sound of its bells following the course of the Sun is a specially useful reference in foggy and rainy days to the people who work in the fields around it. The horizon and firmness of the soil, the streets, paths and fields; the horizontal line of the ground, above whom the vertical line of Life and decadence toward Death are defined; the Sky, day and night, and the phases of the Moon, indicating the right time to cultivate; and, above all, the house. As BACHELARD wrote, "all really inhabited space bears the essence of the notion of house"i. The landscape, the Sky and the village are also a part of the house. However, fundamentally the house is made up by walls and roof, under which some rooms meeting the needs of life and intimacy. Here HEIDEGGER points out that "to inhabit means to be a mortal being on earth"ii. This inhabiting is a "spacing", a creation of space, for humans to be next to things and take care of them. Only this capacity to create spaces enables construction, and especially construction in tune with the Earth and the Sky. What HeIDEGGER calls the quaternity: living on Earth, under the Sky, in the company of men and awaiting for the gods. ¿How, otherwise, could we explain the cosmicity of those old houses perfectly oriented (as orientation is sacred)?

The mass-man of big cities lives with little space. In the metropolis there is no horizon, no belfry standing up, no horizontal line of the ground, almost no sky. ¿How about will this not enable dizziness and disorientation? Even more, in the city there are no houses anymore: flats are piled up boxes, without ground beneath, without roof above. "The house is not familiar anymore with the dramas of the Universe (...) it does not shiver under thunders. It does not tremble with us and for us. "iii Thus, even living in the ninth floor of a twenty-storey building, that box does not mean verticality over the horizontality of the ground. That babelian and fragile verticality is built over the emptiness. There is no firm soil anymore. Other storeys are under the floor; cars circulate underneath; and trains, and drains. Also, there is the noise from machines. The whole city is a big machine "Everything is machine and intimate life escapes through everywhere." ${ }^{\text {iv }}$ The worst futuristic nightmares are sketched as hypertrophies of the city. Rural life does not know those vertigos.

One could think that there is certain resemblance between the Sky Dome and cyberspace, because also cyberspace seems to send us to the fifth element ether. However, a gaping chasm opens between them. ¿What does the network labyrinth Internet is represented by have to do with the uniform pace of Sky Dome? Sky Dome is an expression of immensity, Internet is an expression of complexity.

From different perspectives, some predict and celebrate the fact that houses (or better, "telehouses") will be placed in "another space", in a way that will allow people to be closer to other people living thousands of miles away than to their own neighbours (which, by the way, is not such a big 
deal). Where these houses are settled physically and geographically is of no relevance. Through the windows in the telehouse everyone will see what they wish to: a snowy landscape, the neighbourhood market, a wild mountain, a sports stadium or the bottom of the sea. ¿Does that mean that the house will have a situation? ¿Will the house have a space? ¿Will it win space? In Telepolis, streets do not carry out their basic social functions anymore. Given that "everything" can be done from home, streets and squares quit the faint role they still played. In Telépolis one can find another type of streets, those where information circulates, however floorless they are. Some authors even sustain that deterritorialisation is the condition to cosmopolitism: "In two words: telehouses are breaking the spacetime circle homes had been reduced to by their social environment, and are enabling urbanisation and even cosmopolitisation of domestic domains. Through them civilization has entered the domus, struggling hard against local cultures so far prevailing." Apart from the fact that this is a very debatable thesis, even in its core, I would like to stress that deterritorialization is not only the superation of the boundaries but also the loss of the horizontal line of the ground and the loss of space, with all the consequences derived from this.

What strikes me as really significant is that geographical location is considered to be a limitation to overcome. "Like hyper text overcomes the limitations of printed pages, the era of postinformation will overcome restrictions imposed by geographical location. "vi Human corporeity is incomprehensibly forgotten, to whom space-time limitation is not a limit to overcome but a condition of possibility. Or at least: it is not obvious that the body is an obstacle.

We are in a process of increasing abstraction and cyberspace is hardly a space. This is the same abstraction that does not get on well with the experience of particularities, concretions and boundaries of what is local. Of course place and cyberspace are two different items and best thing we could do is not confuse them and, if still possible, abiding by the old saying: "nothing in excess". A good maxim to avoid falling into the temptation to present things in terms of "exceeding" or "evolution".

Proceedings of the symposium "Localizing the Internet. Ethical Issues in Intercultural Perspective" sponsored by Volkswagen*Stiftung*, 4-6 October 2004, Zentrum für Kunst und Medientechnologie (ZKM, Karlsruhe)
' Bachelard, La poética del espacio. México, FCE, 1998, p. 35.

ii Cfr. Heldegger, "Construir, habitar, pensar", en Conferencias y artículos. Barcelona: Serbal, 1994.

iii BACHELARD, op. cit, p. 58.

iv BACHELARD, op. cit., p. 58.

$\checkmark$ ECheVerría, Cosmopolitas domésticos. Barcelona: Anagrama, 1995, p. 199.

vi Negroponte, El mundo digital. p. 198. 